\title{
Effect of Several Sweet Substances on the Electrical Characteristics of a Dioleyl Phosphate-millipore Membrane
}

\author{
Satoru Iryama, Kiyoshi ToKo, ${ }^{*}$ Kenshi Hayashi* \\ and Kaoru YAMAFUJ * \\ Department of Home Economics, Women's Junior College of Kinki University, \\ Iizuka 820, Japan \\ * Department of Electronics, Faculty of Engineering, Kyushu University, \\ 36, Fukuoka 812, Japan \\ Received September 8, 1988
}

\begin{abstract}
Sweet substances (sucrose, lactose, glucose, fructose, galactose, glycerin and aspartame), excepting Na saccharin, effectively interacted with a negatively-charged lipid membrane of dioleyl phosphate (DOPH). These sweet substances decreased the membrane resistance and depolarized the membrane potential. This response differed from those to bitter, sour and salty substances. Together with the result for transient response, it is suggested that sweet substances could penetrate the lipid membrane. Mono- and disaccharides exerted their effects at a concentration corresponding to the threshold value of taste sensation in vivo. Aspartame, which is about 100-fold sweeter than sucrose, was effective at one-hundredth of this concentration. In addition, the effect of sweet substances on a positively-charged lipid membrane was studied. Changes in the membrane electrical potential and resistance were observed by employing $\mathrm{Na}$ saccharin, which had no effect on the DOPH membrane.
\end{abstract}

Taste reception occurs on the gustatory receptor membrane, which is mainly composed of lipids and proteins. Stimulation of the taste cells results in a change in membrane potential, which is usually called the receptor potential. $^{1 \sim 3)}$

A DOPH (dioleyl phosphate) Millipore membrane is composed of a Millipore cellulose-ester filter, whose pores are choked with a synthetic lipid, DOPH, that is negactively charged at neutral $\mathrm{pH}$ levels. ${ }^{4 \sim 6)}$ This membrane is electrically excitable due to a conformational change in the DOPH molecules within the pores, the electrical response of the membrane to taste stimuli resembling the receptor potential in the taste cells. ${ }^{7,8)}$ In addition, changes of the membrane in electrical potential and electrical resistance are characteristic to each taste stimulus. These results imply that this synthetic lipid membrane can be used as a taste sensor of the biomimetic type.

Among the four basic taste substances, sour, salty and bitter substances are considered to act on the lipids of the biological membrane. With a model membrane composed of monolayers of lipids from bovine taste papillae, it has been elucidated that sour and salty substances interacted with the polar groups of phospholipids within the membrane, and that bitter substances penetrated the non-polar region of the membrane. ${ }^{9 \sim 11)}$ Regarding bitter substances, however, the charged region in addition could not be ignored for their function. ${ }^{7}$ )

In the preceding paper, ${ }^{8)}$ it was found that sucrose affected the electrical properties of a DOPH Millipore membrane. The result suggested the possibility that sweet substances also interacted with lipids. In the present paper, the effect of various sweet substances on the electrical properties of the DOPH Millipore membrane was investigated systematically. Furthermore, the effect of sweet substances on a positively-charged lipid membrane was studied to confirm the participation of an electrical interaction between chemicals and the membrane. 


\section{Materials and Methods}

Sweet substances. Aspartame ( $N$-L- $\alpha$-aspartyl-L-phenylalanine methyl ester) was obtained from Tokyo Kasei Kogyo and was also kindly offered by Ajinomoto Co., Inc.; all the other chemicals used were of analyticalgrade purity.

DOPH Millipore membrane. A membrane was prepared by the same method as that reported previously. ${ }^{4 \sim 8)}$ DOPH was synthesized by hydrolyzing the reactant of oleyl alcohol and phosphorus oxychloride. A Millipore filter (Millipore Corp.) of ceilulose ester with a normal pore size of $5 \mu \mathrm{m}$ was immersed for one minute in a solution of DOPH in benzene, and then dried in air. The quantity of DOPH adsorbed within the filter was adjusted to about $3 \mathrm{mg} / \mathrm{cm}^{2}$ by regulating the concentration of the DOPH-benzene solution. The DOPH Millipore membrane was conditioned in a $100 \mathrm{~mm}$ potassium chloride solution for $12 \mathrm{hr}$, and was later immersed in a $1 \mathrm{~mm}$ potassium chloride solution for a few hours more.

Measurement of the membrane potential and membrane resistance. A DOPH Millipore membrane was placed between two cells, as shown in Fig. 1. One cell was filled with $100 \mathrm{~mm}$ potassium chloride and the other by $1 \mathrm{~mm}$ potassium chloride. Both cells had a circular opening so that each potassium chloride solution could come into contact with the membrane. The membrane potential was detected with $\mathrm{Ag} \cdot \mathrm{AgCl}$ electrodes via two salt bridges, and was recorded with a chart recorder (Riken Denshi F$42 \mathrm{CP}$ ) through a high-impedence transducer with a gain of unity. The membrane resistance was evaluated by measuring the potential change accompanying the application of

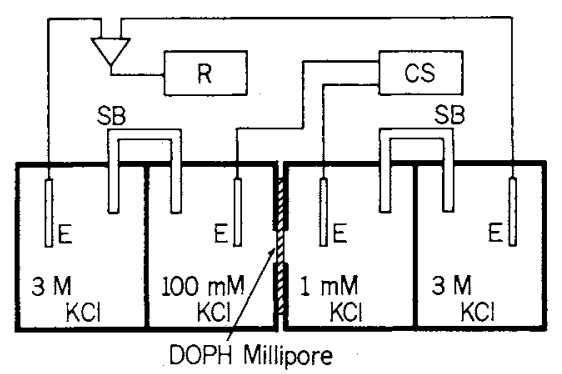

Fig. 1. Experimental Apparatus.

A DOPH Millipore membrane was placed between two cells containing $1 \mathrm{~mm}$ and $100 \mathrm{~mm}$ potassium chloride solutions. The electrical potential was measured with $\mathrm{Ag} \cdot \mathrm{AgCl}$ electrodes (E) via two salt bridges (SB), and was recorded on a chart recorder $(\mathrm{R})$. The membrane resistance was evaluated by the potential change accompanying the application of a weak current, which was supplied with a current sweeper (CS). Sweet substances were added to the $1 \mathrm{~mm}$ potassium chloride solution. a $0.01 \mu \mathrm{A}$ electric current.

Treatment with sweet substances. Concentrated solutions of each sweet substance were prepared. One mm potassium chloride was added to each solution and the $\mathrm{pH}$ was adjusted to a neutral value. The sweet substances were added to the $1 \mathrm{~mm}$ potassium chloride solution, which was stirred throughout the experiments, the concentration of each sweet substance being increased stepwise at $30 \mathrm{~min}$ intervals. The membrane potential was recorded continuously, but the membrane resistance was determined at the end of each treatment. The temperature was kept at $25 \pm 1{ }^{\circ} \mathrm{C}$.

Membrane cast by multi-bilayer-polymer complexes $\left(2 C_{18} N^{+}-P S S^{-}\right)$. The synthetic lipid was dialkyldimethylammonium bromide $\left(2 \mathrm{C}_{18} \mathrm{~N}^{+} \mathrm{Br}^{-}\right)$and the polymer was sodium polystyrenesulfonate $\left(\mathrm{Na}^{+} \mathrm{PSS}^{-}\right.$), the lipid being positively charged at neutral $\mathrm{pH}$ values. The lipid-polymer complexes were cast on a silicon film of $350 \mu \mathrm{m}$ thickness with a pore of $50 \mu \mathrm{m}$ diameter. This type of thin film with a fine pore was also developed for investigating the electrical oscillation of an artificial membrane for chemical sensors. ${ }^{12)}$ Experimental details were similar to the foregoing case of the DOPH membrane, as mentioned previously. ${ }^{13}$ )

\section{Results}

\section{Response of the lipid membrane to sweet substances}

Sucrose, lactose, glucose, fructose and galactose were used as typical sweet stimuli, the sweetness of these substances being of the same order. ${ }^{14)}$ Other sweet substances employed were glycerin, $\mathrm{Na}$ saccharin and aspartame, glycerin ${ }^{3)}$ having the same sweetness as the foregoing sugars. Aspartame ${ }^{15)}$ and $\mathrm{Na}$ saccharin $^{16)}$ are $100 \sim 200$ and $300 \sim 500$-fold sweeter than sucrose, respectively. Tasteless starch was used for a control experiment.

Figure 2 shows the dynamic response of the membrane potential to each sweet substance. The electrical potential of the untreated membrane was $c a$. $-118 \mathrm{mV}$, although the value differed between -.100 to $-125 \mathrm{mV}$ for each membrane preparation. The negative value for the potential means that the membrane has a fine permeability to cations due to the negatively charged phosphate group in the lipid DOPH. Vigorous stirring of the solution decreased the potential by 5 to $7 \mathrm{mV}$, compared with no stirring. However, it was fairly stable 

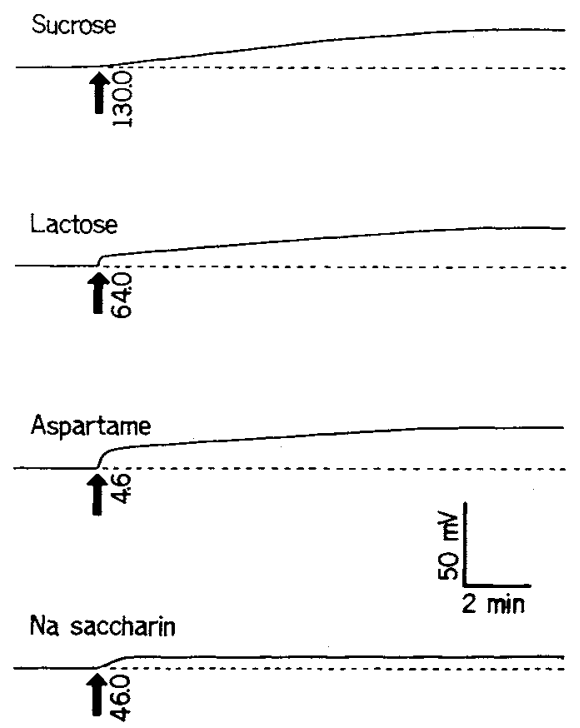

Fig. 2. Transient Profiles of the Electrical Potential.

The time of application for each substance is shown with an arrow, and numerical figures attached to the arrows refer to the concentrations (mM) of substances. Since the electrical potential was originally negative, these changes mean depolarization.

with consistent stirring.

Sucrose progressively decreased the membrane potential, this decrease meaning depolarization, because the initial potential was negative. The rate of depolarization was about $0.03 \mathrm{mV} / \mathrm{sec}$. Glucose, fructose, galactose and glycerin exhibited similar responses to that of sucrose (data not shown), and this level of response, therefore, could be classified as a sucrose type for convenience. The responses to lactose and aspartame consisted of two phases, namely the fast and slow phases, the slow phase resembling the sucrose type. $\mathrm{Na}$ saccharin also changed the membrane potential, although such a response has also been observed by $\mathrm{NaCl}$ treatment. ${ }^{8}$ ) Thus, the response would be attributable to $\mathrm{Na}^{+}$. However, the sucrose type of response could not be seen with the $\mathrm{Na}$ saccharin treatment.

\section{Effect of sweet substances on the membrane potential}

The effect of sweet substances on the potential of the DOPH Millipore membrane is summarized in Fig. 3, showing the potential change as a function of the taste substance concentration. Experiments were carried out about 5 times for each sweet substance, and similar results were obtained for the same substance; a typical one is presented. As already mentioned, the potential of the untreated membrane differed a little for each preparation, and it is presented as a relative value. As one example from the glucose treatment, the application of zero (i.e., control), $0.7,2.6,9.2,28.5,90.5,225$ and $645 \mathrm{~mm}$ glucose changed the potential to $118( \pm 4.8), 118$ $( \pm 4.8), 118( \pm 4.8), 118( \pm 3.2), 112( \pm 7.2), 93$ $( \pm 8.1), 88( \pm 9.4)$ and $87( \pm 9.3) \mathrm{mV}$, respectively. Numerals in parentheses indicate the standard deviation in $\mathrm{mV}$.

With an increase in the concentration of each sweet substance, the potential was decreased. All sugars except starch affected the membrane potential at concentrations near $0.01 \sim 0.1 \mathrm{M}$. Tasteless starch alone hyperpolarized the membrane potential a little. Glycerin, whose sweetness is at the same level as the sugars, also decreased the potential at a comparable concentration. The concentration at which aspartame exerted its effect was about two orders lower than sugars, and $\mathrm{Na}$ saccharin seemingly decreased the potential. As mentioned in Fig. 2, this decrease appears to have depended on $\mathrm{Na}^{+}$, since $\mathrm{Na}^{+}$ions depolarize the membrane potential. ${ }^{8)}$ If the contribution of $\mathrm{Na}^{+}$was substracted, therefore, the effect of saccharin disappeared, as shown in Fig. 3.

\section{Effect of sweet substances on the membrane resistance}

The effect of sweet substances on the membrane resistance is shown in Fig. 4. The untreated resistance value was 4 to $10 \mathrm{M} \Omega$, depending on the membrane preparation; hence, it is displayed as a relative value. With the glucose treatment, as one example, zero (i.e., control), 0.7, 2.6, 9.2, 28.5, 90.5, 225 and $645 \mathrm{mM}$ glucose produced the resistances of 5.3 $( \pm 1.1), 5.6( \pm 1.2), 5.8( \pm 1.3), 5.8( \pm 1.4), 5.4$ $( \pm 1.3), 3.6( \pm 0.7), 1.9( \pm 0.8)$ and $1.8( \pm$ $0.8) \mathrm{M} \Omega$, respectively, with numerals in par- 


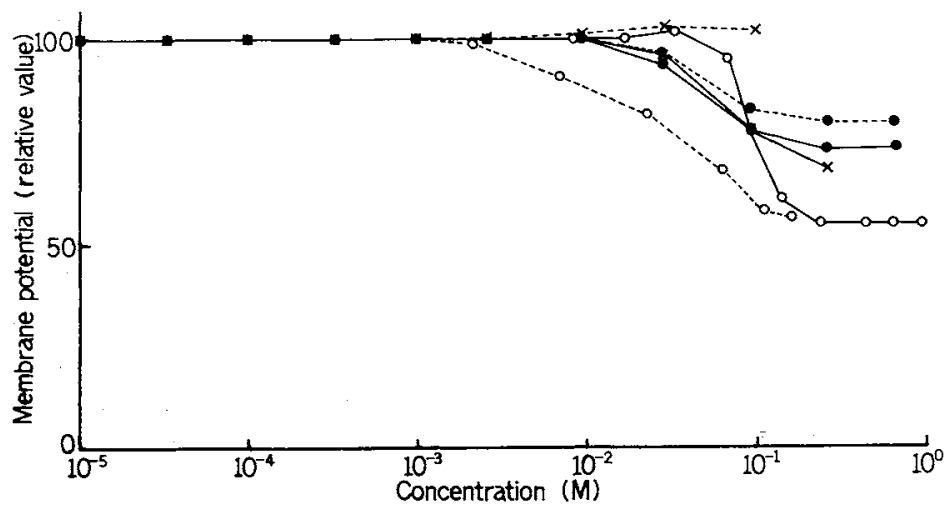

(a)

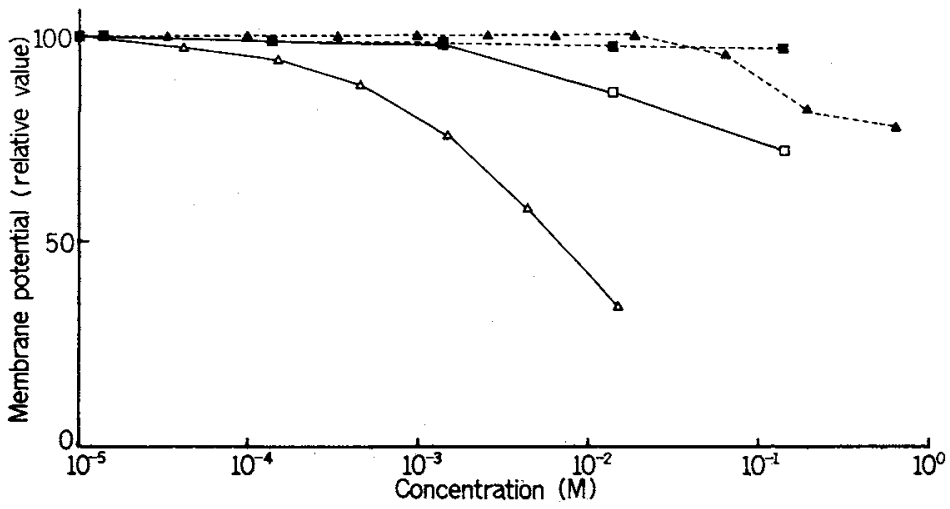

(b)

Fig. 3. Depolarization of Electric Potential by Sweet Substances.

The initial membrane potentials differed a little for each membrane, and the values were normalized as a relative value of 100 . When the initial potential was $-118 \mathrm{mV}$ and it was decreased to $-59 \mathrm{mV}$, this is represented as 50 . The concentration of starch is displayed by that of the residue, namely glucose. (a) Effect of sugars: - - - , sucrose; --- ---, lactose; - - - glucose; -- ---, fructose; - $\times-$, galactose; --- $x_{---}^{-}$, starch.

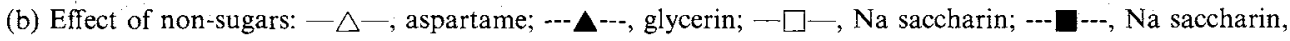
where the contribution of $\mathrm{Na}^{+}$has been subtracted.

entheses indicating the standard deviation. The deviation was larger than that of the membrane potential.

Sweet substances thus altered the membrane resistance, but in a somewhat complicated manner. With increasing concentration, the resistance was slightly increased up to the point where further increase decreased the resistance markedly. This characteristic held for all sweet substances except $\mathrm{Na}$ saccharin. The concentration of each sweet substance at which the resistance was decreased coincides with the concentration affecting the potential shown in Fig. 3. Na saccharin had no influence on the resistance, and starch increased the resistance to some extent.

\section{Effect on the $2 C_{18} N^{+}-P S S^{-}$membrane}

The DOPH Millipore membrane is sensitive to cations because of its negative charge, while the $2 \mathrm{C}_{18} \mathrm{~N}^{+}-\mathrm{PSS}^{-}$membrane shows a potential characteristic to the positively-charged lipid membrance. ${ }^{13,17)}$ When no taste substance was added, the electrical potential was stable at $110.8 \pm 0.7 \mathrm{mV}$. Figure 5 shows typical examples of changes in the membrane potential 


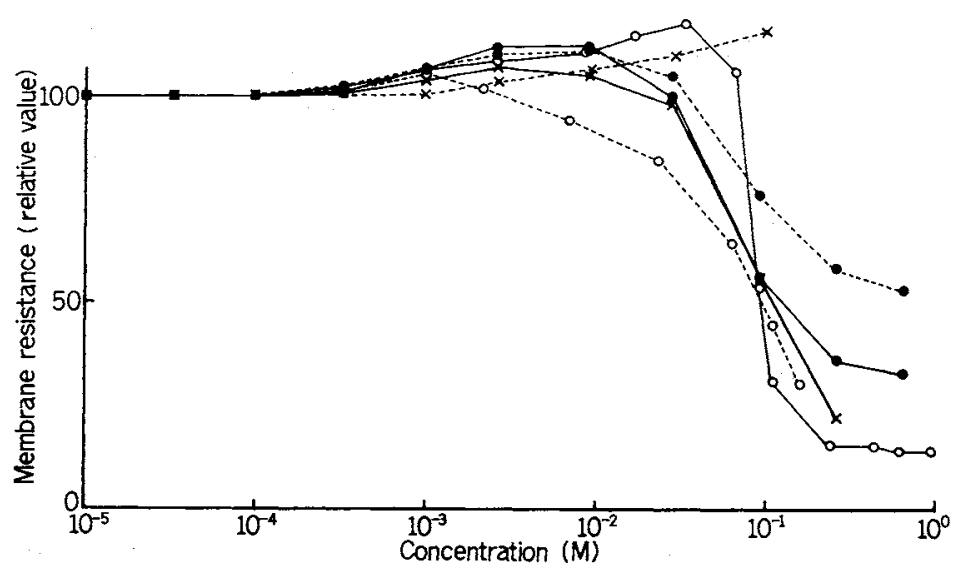

(a)

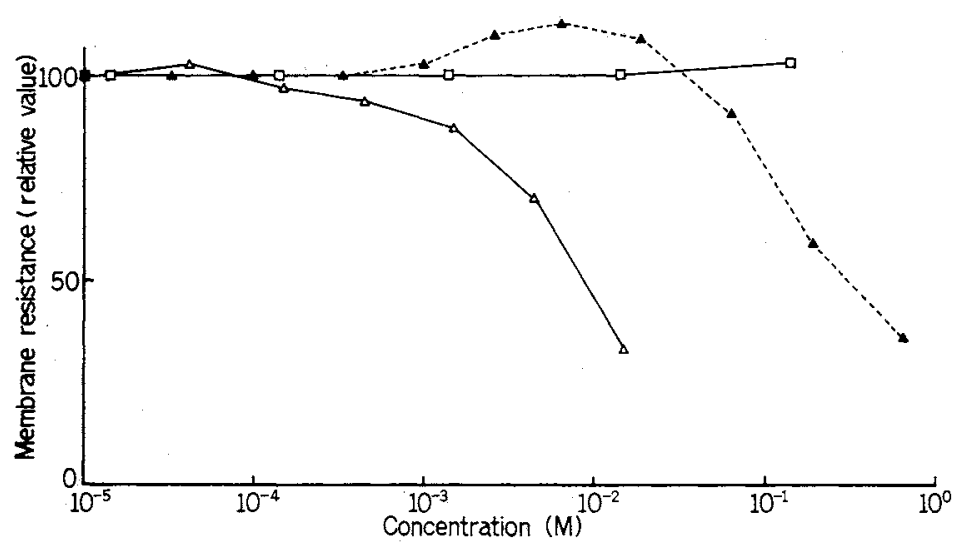

(b)

Fig. 4. Change of Membrane Resistance by Sweet Substances.

The ordinate, membrane resistance, was normalized in the same manner as that in Fig. 3. (a) Effect of sugars: $-\bigcirc-$, sucrose; -- $\bigcirc---$, lactose; - - - glucose; --- ---, fructose; - $-\times-$, galactose; --- $\times---$, starch. (b) Effect of non-sugars: $-\triangle-$, aspartame; --- $\mathbf{A}^{---}$, glycerin; - $\square--$, Na saccharin.

and the resistance with $\mathrm{Na}$ saccharin, sucrose and aspartame. With $\mathrm{Na}$ saccharin, the membrane potentials were $109.2( \pm 0.7), 109.3$ $( \pm 0.9), \quad 107.4( \pm 0.9), \quad 101.3( \pm 1.1), 84.2$ $( \pm 2.4), 62.9( \pm 3.8), 35.9( \pm 5.5), 10.9( \pm 8.0)$, $-4.6( \pm 8.0),-7.5( \pm 5.8)$ and $2.1( \pm 5.3) \mathrm{mV}$ for $0.01,0.03,0.1,0.3,1,3,10,30,100,300$ and $850 \mathrm{~mm}$ Na saccharin, respectively. The respective membrane resistances were 7.4 $( \pm 1.6) \mathrm{M} \Omega$ for the control and $7.9( \pm 1.8), 8.1$ $( \pm 1.8), 8.6( \pm 1.8), 9.3( \pm 1.9), 10.5( \pm 2.1)$, $11.3( \pm 2.2), 12.2( \pm 2.6), 12.7( \pm 2.5), 12.3$ $( \pm 2.1), 9.1( \pm 5.2)$ and $0.01( \pm 0.03) \mathrm{M} \Omega$ for $\mathrm{Na}$ saccharin.
While $\mathrm{Na}$ saccharin markedly affected the membrane electrical properties, sucrose and aspartame did not. This result is opposite to the case of the DOPH membrane, implying the participation of an electrical interaction between sweet substances and the membrane. Furthermore, the membrane potential became minus at higher concentrations of $\mathrm{Na}$ saccharin, which may reflect the strong binding of saccharin anions to lipid-polymer complexes.

\section{Discussion}

In biological systems, sweet substances have 


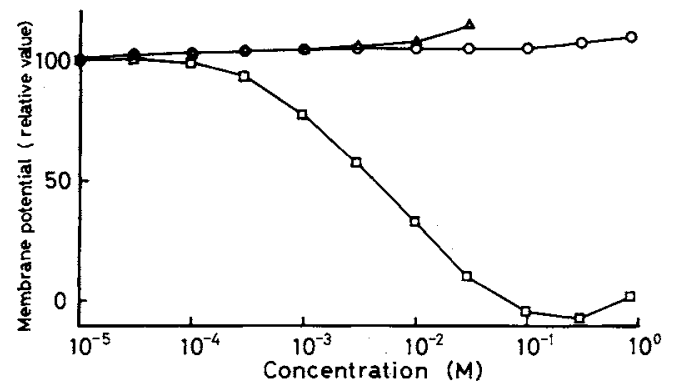

(a)

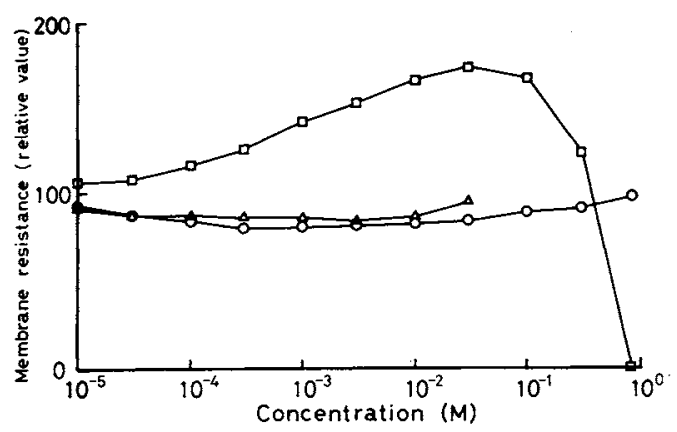

(b)

Fig. 5. Changes in the Electrical Potential. (a) and Electrical Resistance (b) of a $2 \mathrm{C}_{18} \mathrm{~N}^{+}-\mathrm{PSS}^{-}$Membrane with Sweet Substances.

The relative value $100 \mathrm{in}$ (a) corresponds to $c a .+111 \mathrm{mV}$, that in (b) referring to $c a .8 \mathrm{~m} \Omega$. The membrane potential shows a positive value, contrary to the DOPH membrane, implying that the $2 \mathrm{C}_{18} \mathrm{~N}^{+}-\mathrm{PSS}^{-}$membrane was sensitive to anions. $-\square-$, Na saccharin; $-\mathrm{O}-$, sucrose; $-\triangle-$, aspartame.

been presumed to interact with proteins in the membrane. ${ }^{18)}$ The leaves of Gymnema sylvestre selectively suppressed the sensitivity to sweet substances, ${ }^{19)}$ and a protein which combined with sweet substances was extracted from bovine tongues. ${ }^{20,21)}$ Moreover, taste responses to sugars and amino acids were selectively eliminated by the application of a proteolytic enzyme to a rat tongue. ${ }^{22)}$ Although investigations to find the receptor proteins have been carried out, ${ }^{23,24)}$ model membranes have rarely been studied from the viewpoint of their interaction with sweet substances. Recently, it has been suggested that saccharides may interact with lipid membranes. ${ }^{25}$ )

We have investigated the effect of sweet substances on a synthetic lipid membrane in order to develop a taste sensing system. ${ }^{6,7)} \mathrm{All}$ of them except $\mathrm{Na}$ saccharin affected a DOPH Millipore membrane in the same manner (Figs. 3 and 4), depolarizing the membrane potential and decreasing the membrane resistance. The threshold concentration above which sugars had an effect on the membrane potential was about $10^{-2} \mathrm{M}$, this being of the same order as the value obtained in a real system. The synthetic sweetener, aspartame, was more effective than sugar by about 100 -fold, which also agrees with our taste sensation.

Sweet substances simultaneously decreased the membrane potential and the membrane resistance of the DOPH system. Their action differs from that of other taste stimulants, because bitter, sour and salty substances decreased only the membrane potential. ${ }^{7,8)}$

Sucrose slowly depolarized the membrane potential (Fig. 2), and others also had similar characteristics. It has been suggested ${ }^{8)}$ that sweet substances penetrate the membrane gradually to decrease the membrane resistance and depolarize the membrane potential. As a result, they would affect the diffusion potential within the membrane. The response rate of sucrose was $0.03 \mathrm{mV} / \mathrm{sec}$, which is slower than that observed in vivo by one order. ${ }^{26 \sim 28)}$ This slow response could have been attributable to the thickness of the membrane, the thickness of the biomembrane and the DOPH Millipore membrane being $10^{-8} \mathrm{~m}$ and $10^{-4} \mathrm{~m}$, respectively.

$\mathrm{Na}$ saccharin is $300 \sim 500$-fold sweeter than sucrose, although it had no effect on the DOPH membrane. This may be purely due to an electrochemical effect, because, in $\mathrm{Na}$ saccharin, part of the saccharin is charged negatively at neutral $\mathrm{pH}$ values. ${ }^{3)}$ The phosphate group of DOPH is charged negatively in the same manner, and mutual repulsion between the negatively charged saccharin and DOPH would make physical contact impossible. In fact, the $2 \mathrm{C}_{18} \mathrm{~N}^{+}-\mathrm{PSS}^{-}$membrane responded to Na saccharin (Fig. 5), this membrane being sensitive to anions because of the positive charge of the lipid. ${ }^{13,17)}$ These results suggest 
the importance of electrical interaction between sweet substances and the membrane, as was also shown for bitter substances. ${ }^{7)}$

Sucrose reacted with DOPH, but not with $2 \mathrm{C}_{18} \mathrm{~N}^{+} . \mathrm{PSS}^{-}$. This can be explained by a similar electrochemical consideration, because sucrose dissolves in water by making a hydrogen bond. The hydroxyl group of sugar is linked to a partly negative oxygen atom of the water molecule, and thus, the functional group of sugar would be more reactive with the negatively charged $\mathrm{DOPH}$ than with the positively charged $2 \mathrm{C}_{18} \mathrm{~N}^{+}$through the formation of the hydrogen bond.

In the present work, two types of adsorbed and cast membranes were studied. Recently, the Langmuir-Blodgett (LB) film has been presented as a new type of chemical sensor by utilizing various lipids. ${ }^{29)}$ The present resuits provide fundamental data for the construction of a taste sensing system when used in conjunction with previous results. ${ }^{6 \sim 8.13 \text { ) }}$

\section{References}

1) L. M. Beidler, J. Gen. Physiol., 38, 133 (1954).

2) M. Sato, "Handbook of Sensory Physiology," Vol. IV, Part 2, ed. by L. M. Beidler, Springer-Verlag, Heidelberg, 1971, p. 116.

3) C. Pfaffmann, "Handbook of Physiology," Sec. 1, Neurophysiology, Vol. 1, ed. by J. Field, American Physiological Society, Washington D. C., 1959, p. 507.

4) Y. Kobatake, Adv. Chem. Phys., 29, 319 (1975).

5) K. Toko, M. Tsukiji, S. Ezaki and K. Yamafuji, Biophys. Chem., 20, 39 (1984).

6) K. Toko, M. Tsukiji, S. Iiyama and K. Yamafuji, Biophys. Chem., 23, 201 (1985).
7) S. Iiyama, K. Toko and K. Yamafuji, Agric. Biol. Chem., 50, 2709 (1986).

8) S. Iiyama, K. Toko and K. Yamafuji, Maku (Membrane), 12, 231 (1987).

9) M. Miyake, N. Kamo, K. Kurihara and Y. Kobatake, J. Membrane Biol., 22, 197 (1975).

10) M. Miyake, N. Kamo, K. Kurihara and Y. Kobatake, Biochim. Biophys. Acta, 436, 856 (1976).

11) K. Kurihara, K. Yoshii and M. Kashiwayanagi, Comp. Biochem. Physiol., 85A, 1 (1986).

12) K. Shimoide, Z. Qingde and T. Moriizumi, Jpn. J. Appl. Phys., 25, L569 (1986).

13) K. Toko, K. Hayashi, S. Ijyama and K. Yamafuji, Dig. Tech. Papers of Transducers 87, 793 (1987).

14) A. Biester, M. W. Wood and C. S. Wahlin, Am. J. Physiol., 73, 387 (1925).

15) R. H. Mazur, J. M. Schlatter and A. H. Goldkamp, J. Am. Chem. Soc., 91, 2684 (1969).

16) R. A. Bernard, Am. J. Physiol., 206, 827 (1964).

17) K. Toko, N. Nakashima, S. Iiyama, K. Yamafuji and K. Kunitake, Chem. Lett., 1986, 1375.

18) R. S. Shallenberger, T. E. Acree and C. Y. Lee, Nature, 221, 555 (1969).

19) W. Stocklin, E. Weiss and T. Reichstein, Helv. Chim. Acta, 50, 474 (1967).

20) F. R. Dastoli and S. Prise, Science, 154, 905 (1966).

21) H. R. Cagan, Biochim. Biophys. Acta, 252, 199 (1971).

22) Y. Hiji, Nature, 256, 427 (1975).

23) C. Lo and T. Ma, Biochim. Biophys. Acta, 307, 343 (1973).

24) C. K. L. Lum and R. I. Henkin, Biochim. Biophys. Acta, 421, 380 (1976).

25) K. Miyajima, Maku (Membrane),12, 250 (1987).

26) K. Kimura and L. M. Beidler, J. Cell. Comp. Physiol., 58, 131 (1961).

27) M. Ozeki and M. Sato, Comp. Biochem. Physiol., 41A, 391 (1972).

28) N. Akaike, A. Noma and M. Sato, J. Physiol., 254, 87 (1976).

29) T. Moriizumi, Thin Solid Films, 160, 413 (1988). 